\title{
Reproductive autonomy: A case study
}

\author{
D R Hall, ${ }^{1}$ MPhil, MD; A A van Niekerk, ${ }^{2}$ DPhil \\ 'Department of Obstetrics and Gynaecology, Stellenbosch University and Tygerberg Hospital, Cape Town, South Africa \\ ${ }^{2}$ Centre for Applied Ethics, Department of Philosophy, Stellenbosch University, Cape Town, South Africa
}

\section{Corresponding author: D R Hall (drh@sun.ac.za)}

\begin{abstract}
Reproductive autonomy (RA) has been challenged by the availability of genetic information, disability and the ethics of selective reproduction. Utilitarian and rights-based approaches, as well as procreative beneficence (PB) fail to provide compelling reasons for infringing RA, and may even be likened to dangerous eugenics. Parents are not morally obliged to prevent the birth of a disabled child. Society should rather adopt inclusivity, recognising and providing persons with disabilities opportunities for capability and worthwhile lives.
\end{abstract}

S Afr J Bioethics Law 2016;9(2):61-64. DOI:10.7196/SAJBL.2016.v9i2.496

The range of genetic conditions and fetal anomalies detectable before or in early pregnancy is enlarging continuously, making pregnancy a minefield of complex ethical problems. Prenatal genetic and anomaly counselling and testing are now part of routine antenatal care. The main goals of this service are to provide counselling before proceeding with pregnancy or to identify affected fetuses in order to inform and offer parents choices on whether to continue with certain pregnancies, but several dangers arise. Pregnancy becomes tentative and provisional, instead of an unconditional acceptance as a 'gift of God!.[1] Women are encouraged to expect a 'perfect baby', disability is medicalised and screening technologies endorse discrimination against those who live meaningful lives with the very impairments that are tested for. The following challenging case was managed in the Obstetric Special Care division at Tygerberg Academic Hospital, Cape Town. This patient granted full informed consent for a case discussion.

\section{Presenting problem}

Mrs X was 22 years old with non-lethal osteogenesis imperfecta (OI), a congenital, genetic condition that had caused her short stature and severe scoliosis. She presented at 24 weeks 2 days gestation during her second pregnancy after moving to South Africa (SA) from England. This pregnancy was desired and welcome. Her first pregnancy was terminated early on request. Ol is an inherited (autosomal dominant - $50 \%$ chance), severely debilitating condition with brittle bones that fracture easily. Fractures start during intra-uterine life and the baby is born with deformities. Scoliosis compromises mobility and complicates childbirth. Mrs $\mathrm{X}$ had multiple previous fractures, including bilateral femur, and a pelvic fracture. She had undergone several operations to stabilise these fractures. Her short stature, scoliosis and deformities caused a constant, moderate dyspnoea. By religious conviction she was a Jehovah's Witness (JW), who did not smoke or drink alcohol. Prior to the pregnancy she was completely self-sufficient.

\section{Course of pregnancy}

Apart from her skeletal problems, other organ functions were normal. Detailed ultrasound examination of her fetus revealed characteristic Ol fractures in different stages of healing. Importantly, there were no rib fractures and the chest was normal. Mrs X's baseline function started changing at 22 weeks' gestation, with painful legs and back, difficulty walking and sleeping. At 28 weeks she required a wheelchair for daily activities. Because vaginal delivery was not deemed possible, an elective caesarean section was planned at 37 weeks while careful monitoring continued. The possibility of blood transfusion was sensitively discussed due to her JW faith. She was comfortable with this, provided that it was regarded as life saving and that there were no alternatives.

At 35 weeks 2 days Mrs $\mathrm{X}$ was readmitted with significantly deteriorating respiratory function and was delivered by caesarean section 1 day later. Special precautions were taken during the anaesthetic and surgery, and a male baby (2 $480 \mathrm{~g})$ was born in good condition. Mrs $\mathrm{X}$ declined the offer of sterilisation but opted for an intra-uterine contraceptive device, which was inserted during surgery. Following the delivery she was admitted to a critical care unit for observation, but recovered quickly without complications or a blood transfusion. She and her baby were discharged 6 days after delivery. This case clearly touches many issues but we will focus on reproductive autonomy (RA).

\section{Reproductive autonomy}

Reproductive autonomy represents the strong interest or right to make choices regarding reproduction even when others might regard such choices as unwise or against public interest. Dworkin, a philosopher and legal theorist, describes the RA of persons as 'a right to control their own role in procreation unless the state has a compelling reason for denying them that control. ${ }^{[2]}$ In modern life, genetic information is increasingly available and society is 'policed' by advocates of responsible motherhood ${ }^{[3]}$ Therefore it could be argued that society may become increasingly critical of those who, in its opinion, make the wrong reproductive decisions although this does not in itself make the decisions immoral.

\section{Freedom to procreate}

Why do individuals value having genetically related children, through natural procreation, so highly? Strong argues that such children affirm a couple's love and provide a link to future persons, but he rejects the 
notion that men must prove their virility and women their femininity through children ${ }^{[4]}$ Most women experience pregnancy and the joy of childbirth as deeply meaningful and valuable. Pregnant women are esteemed by the community and pregnancy provides an experience of personal development and altruism. ${ }^{[4]}$ While genetic links do not guarantee superior social relationships the reasons above do justify the desire for genetic offspring, with procreation contributing to selffulfilment and self-identity. Therefore, interference with these rights may deny necessary respect due to individuals. Although freedom to procreate may be outweighed by other ethical concerns we would require compelling reasons to override it. Next we examine the other end of the spectrum.

\section{Freedom not to procreate}

Several arguments support the value of this seemingly counterintuitive freedom. This 'negative' freedom helps a person direct the course of her or his life. Persons may prefer not to procreate because they are not located within socially acceptable parenting relationships. Having children places major demands on parents' time and resources. Autonomy and self-determination are enhanced by the freedom to decide whether or when to have children. Many women of reproductive age suffer from diseases such as diabetes, hypertension or renal impairment. When a pregnancy would significantly threaten the existing health, or even life of a woman, her freedom not to procreate protects the course of her life. Sadly, women are often coerced by the expectations of partners and society to risk their future health. Freedom not to procreate is closely linked to bodily self-determination. Women have the right to decide on the use of contraceptives and especially sterilisation. Although men also have this right, it is especially important for women due to their previous 'oppression' and the fact that they bear the burdens of pregnancy.

Many feminist authors postulate that male-stream moral theory has both feminised and looked down upon the role of care and relationship in moral decision-making. Gilligan contrasts 'care ethics' with what she calls 'justice or rights ethics' and sees them as loosely feminine and masculine, respectively. ${ }^{[5]}$ Kroeger-Mappes ${ }^{[6]}$ argues that a system of two ethics, with rights presiding over care ethics, is seriously flawed, as women but not men are held accountable to both kinds of ethics. Women are held to the requirements of care ethics, especially in home and family life, in ways that men are not. This subordinates women by viewing caring activities as obligatory for women and as supererogatory for most men. Therefore for women to gain equality, they must be free to regulate their reproductive lives on the basis of liberal, individual rights.

\section{When is it morally wrong to procreate?}

'The idea that it might be a moral crime to have a baby, that it might be wrong to bring a new human individual into the world is to many people simply bizarre. It is only having an abortion and perhaps also refraining from having children that is regarded as requiring justification, ${ }^{[7]}$

At the heart of this debate lies the question of whether a child could be better off if he or she had never been born, known in legal terms as 'wrongful life'. Ultimately, the difference is not about being born impaired rather than unimpaired but 'the difference between being born and not being born - existing and not existing'.8] When there is an early indication (before viability) that an impaired child will be born, is it morally right or wrong to bring that child to birth? Surely, once all interested parties (parents, the potential child, family and society) have received due consideration, it is not wrong to proceed responsibly. Our answer also depends on the value that we place on life and our concept of a worthwhile life. If we generally regard life as valuable and positive then 'unless the child's condition is predicted to be so bad that it would not have a worthwhile life, it will always be in the child's interests to be brought into being ${ }^{\prime[8]}$ as this is this child's only chance of existing at all. We are aware of the book by Benatar ${ }^{[9]}$ in which he argues that it is always worse to come into existence than to never have come into existence. We disagree with this view. Comparing existence with non-existence is problematic. If a person was never born, never existed, then it is illogical to argue that they could be better or worse off. On the other hand, it seems reasonable to consider lives that are worth living and 'those that are so blighted by suffering that they may be considered "unworthwhile"."[8] Utilitarians could argue that it would be cruel to bring such lives into existence, thereby increasing unhappiness, but how would society prevent this without invading individual privacy, bodily integrity and civil liberties?

While Feinberg ${ }^{[10]}$ has suggested that it is morally wrong to bear children who will be born with physical or mental impairment even if their lives are expected to be worthwhile, Bennett and Harris ${ }^{[8]}$ ask 'what if anything is morally wrong about bringing into existence an impaired but worthwhile life?' However, there is a point where Bennett and Harris's opinions diverge. Both defend RA as a 'powerful interest' even 'where these choices may be thought unwise, frivolous or contrary to the public interest'. Both agree that as long as a life is worthwhile, i.e. valued by the person whose life it is, it is equal to any other life regardless of its quality. This applies to all actual lives but Bennett extends it to all possible lives. They agree that only a life of overwhelming suffering has a different value. ${ }^{[8]}$ Very few disabilities reach this 'standard of awfulness'. When someone can only have an impaired or disabled child, it is not morally wrong to do so if it can be judged that the life would be worthwhile. Harris has even stated that 'for those who can only have disabled children, having such children may be morally better than having no children at all! ${ }^{[11]}$

The important point at which the opinions of Bennett and Harris ${ }^{[8]}$ diverge is when parents have the alternative of bearing children who will not be affected by disabilities. Harris argues that if such parents choose to continue with a pregnancy where a disabled child will be born, they needlessly make the world worse by adding suffering. Here'we are not comparing a child's life with or without disability but rather the lives of different possible children'. The wrong lies not in the creation of the life of the child, if it is judged to have a worthwhile life, but in adding avoidable suffering or unhappiness to the world. In this consequentialist argument moral reasons may trump reproductive autonomy. Although we clearly have a strong moral obligation to minimise net suffering, certain disabilities are trivial, and the assumption that the lives of disabled persons contain more suffering than the lives of able-bodied individuals is far from self-evident. If the lives of disabled and able-bodied persons are valued by those who love them they have equal value, even if they have different qualities. This is true in an existential sense and each person has a powerful interest in making his or her life as good as possible.

Bennett on the other hand, believes that these choices are 'genuinely morally indifferent'. Even if parents can potentially bear 
normal children as well, in the choice of bringing a disabled child to birth no one is harmed. 'Those who choose to bring a disabled child to birth are responsible for that decision. If the mother had disabled her "healthy child" by her deliberate actions, then she would be responsible for the harm incurred. However, in the case of a congenital malformation, neither has the child been harmed, nor is the mother morally responsible for that harm by bringing the child to birth. The child has not been harmed as ... these opportunities were never available to him. ${ }^{\prime[8]}$ The child gains existence and although society may prefer normal children, the parents should not be condemned for their choice. ${ }^{[8]}$

\section{Is there a societal duty not to procreate?}

We now extend the 'morally wrong to procreate' argument by briefly discussing the opinions of McHale, ${ }^{[3]}$ a British medical lawyer on whether a duty not to reproduce exists. There is increasing pressure in modern society to give birth to the best possible children. ${ }^{[12]}$ This pressurises women to behave responsibly and make correct reproductive choices, but how far does this argument extend down the slippery slope? Is it limited to choosing to avert significant handicap or does it extend to intelligence and desirable morphologic characteristics? Such language stirs discomfort as it reminds us of eugenics debates. Assisted reproductive technologies already provide a means of controlling access to reproductive services where clinicians select participants according to pre-determined criteria. However, such control does not apply outside the walls of infertility clinics and a general application would at present seem 'ludicrous.[3]

There may be a duty not to procreate if certain harm to the child can be demonstrated. A couple at very high risk for passing on an incurable disorder might want genetically related offspring The emotionally taxing, limited and very expensive option of preimplantation diagnosis is sometimes available but couples might object to the destruction of unused embryos. Would it be morally and legally wrong for them to reproduce without such screening? Although admitting the difficulty of defining a 'minimally satisfying life', Purdy ${ }^{[13]}$ has strongly argued that it is wrong to reproduce when a high chance of transmitting genetic disease, such as Huntington's disease, exists. One may speculate that with the amount of potential genetic information increasing at a rapid pace, even normal couples might feel 'forced' to undergo genetic testing before they reproduce. Therefore further pressure will be placed on making reproductive decisions acceptable to society, as the 'slippery slope' of eugenics looms large. Greater knowledge of a person's genetic status might also have other consequences, e.g. affecting employment or insurance. Even if a duty not to procreate existed, how would it be enforced? Population-based, compulsory testing would be necessary, many fundamental rights would be violated and a law would be impossible to apply consistently (e.g. unplanned pregnancies). McHale $^{[3]}$ also notes that successful 'wrongful life' claims will impose intolerable burdens on the medical profession and encourage pressure to advise abortion in doubtful cases through fear of litigation.

We may ask who should bear the costs of caring for affected children. For indigent parents the cost may have to be carried by the state but does this equate to imposing a duty not to procreate? There is concern about modern society's attitude towards disabled community members. We agree with the view that screening for disabilities in order to prevent them or applying modern technology to lessen the burdens of disability conveys an attitude of intolerance for, or non-acceptance of, disabled people, but to try and prevent disabilities does not necessarily imply rejection of disabled people. ${ }^{[14]}$

\section{The FIGO position}

The recent Federation of International Gynaecology and Obstetrics (FIGO) ${ }^{[15]}$ committee report titled 'Ethical issues in the management of severe congenital anomalies' emphasises that anomalies range from insignificant to severe, with the latter resulting in death or significant mental or physical disability. The lack of a medical definition of both severity of fetal disease and normal life is acknowledged but the very notion of normal is often regarded by disabled persons as a form of discrimination. Because delivering and raising a severely impaired baby may impact the physical, mental and social life of a family, FIGO recommends that women should be informed about the risks and benefits of fetal diagnostic testing regardless of the legal availability of termination of pregnancy. When a severe anomaly is present the woman has the right to discuss and access termination of pregnancy, but that decision as well as the responsibility for its consequences should always rest with her. Despite this strong support of parental autonomy the report states unequivocally that it is unethical to terminate a pregnancy on the grounds of fetal sex alone, with the exception of severe sex-linked, genetic disorders. ${ }^{[15]}$

\section{Selective procreation}

Our generation has at its disposal greater knowledge regarding genetics, assisted reproduction and the diagnosis of fetal anomalies than ever before. This knowledge generates choices, but having more choices does not necessarily make them better. ${ }^{[16]}$ Savulescu's ${ }^{[12]}$ principle of procreative beneficence (PB) states that we have a moral duty to select the best children possible. This makes intuitive sense within the original context (in vitro fertilisation) and when, e.g. a diabetic woman postpones pregnancy while optimising her glycaemic control to avoid fetal congenital anomalies, but PB still remains controversial. ${ }^{[17]}$ Although it is clear that giving birth to a disabled child does not harm that particular child, utilitarians would argue that life quality and costs must be considered, but among the variability of human life, happiness is a complex matter that escapes simple calculation and PB discounts the significance of relationships. Contemporary liberal societies promote the idea of social inclusion of disabled persons, claiming that they can be as happy and productive as able-bodied ones. ${ }^{[18 .}$

In defending selection, consideration could be given to the interests of future persons in terms of inter-generational justice expounded in Parfit's ${ }^{[19]}$ Non-Identity Problem. However, egalitarian principles do not indicate how reasonable parents should 'select' their children, as disabilities may correctly be viewed as natural facts (misfortune) rather than injustices. According to Tong:[20] 'Disability is not a good in itself. Rather it is something with which all human beings, to a greater or lesser degree, must cope, so that they can discover or shape meaning for themselves within its limitations. Children's genes are not their entire destiny'. A rightsbased approach must assume equality and impartiality, which could not justify choosing one life over another. It seems too easy to move from the bad eugenics of the past to present good genomics, but parents have no moral duty to deny less than normal fetuses the prospect of a meaningful life. ${ }^{[20]}$ History leaves ample evidence of 
severely disabled people who made admirable contributions to society, e.g. Hellen Keller (1880 - 1968) who, though deaf, blind and mute as a child, attained university degrees and wrote books, as well as Henri de Toulouse Lautrec (1864 - 1901), a dwarf who was also a famous French painter.

In his examination of selecting healthy children, Jacobs ${ }^{[21]}$ rejects both the 'conservative position of procreative autonomy' and the 'radical position' of PB by opting for a middle path that is informed by the 'moral calculus' of the expected quality of life for any individual child. In this case study our patient had performed that moral calculation. She was fully aware of the spectrum of her disease and had an optimistic, yet realistic personal perspective. From a utilitarian perspective she had robust grounds on which to base her conviction that her life as a parent and the life of her child would be worthwhile. It is a difficult exercise to draw an objective, impassionate line of severity that identifies lives that should not be brought into being. However, when selective procreation does offer the opportunity to prevent significant suffering, it is our responsibility to consider it carefully when dealing with impairments regarded as severe. Ultimately we do well to heed the reminder that irrespective of our differences, humans have moral worth and that although our true identity should be inwardly generated rather than socially derived, the recognition of our lives by significant others, shapes our image and self-esteem. ${ }^{[18]}$ We may not reduce our fellow persons to their genetic characteristics or bodily capacities. This full recognition of human dignity in open, vulnerable love, expressed in the parentchild and other relationships, argues against the general selection of children.

\section{References}

1. Alderson P. Prenatal counselling and images of disability. In: Dickenson D, ed. Ethical Issues in Maternal-Fetal Medicine. Cambridge: Cambridge University Press, 2002:195-212.
2. Dworkin R. Life's Dominion. London: Harper Collins, 1993:148.

3. McHale J. Is there a duty not to reproduce? In: Dickenson D, ed. Ethical Issues in Maternal-Fetal Medicine. Cambridge: Cambridge University Press, 2002:101112.

4. Strong C. Overview. In: Dickenson D, ed. Ethical Issues in Maternal-Fetal Medicine. Cambridge: Cambridge University Press, 2002:101-112.

5. Gilligan C. In a different voice. In: Kemp S, Squires J, eds. Feminisms. Oxford: Oxford University Press, 1997:146-152.

6. Kroeger-Mappes J. The ethic of care vis-à-vis the ethic of rights: A problem for contemporary moral theory. Hypatia 1994;9(3):108-131.

7. Harris J. Clones, Genes and Immortality. Oxford: Oxford University Press, 1998:99-101.

8. Bennett R, Harris J. Are their lives not worth living? When is it morally wrong to reproduce? In: Dickenson D, ed. Ethical Issues in Maternal-Fetal Medicine. Cambridge: Cambridge University Press, 2002:321-334.

9. Benatar D. Better never to have been: The harm of coming into existence. Oxford: Oxford University Press, 2006.

10. Feinberg J. Harm to others. NewYork: Oxford University Press, 1984

11. Harris J. Wonderwoman and superman: The ethics of human biotechnology. Oxford: Oxford University Press, 1992:72.

12. Savulescu J. Procreative beneficence: Why we should select the best children Bioethics 2001;15(5-6):413-426.

13. Purdy L. Reproducing persons: Issues in feminist bioethics. New York: Cornell University Press, 1996:43-46.

14. Van NiekerkAA. Disability and biomedical enhancement: Conflict or co-existence? In: Swartz L, Claassen J, Hansen LD, eds. Searching for Dignity: Conversations on Human Dignity, Theology and Disability. Stellenbosch: Conference-RAP (Sun MeDIA), 2013:103-116.

15. Figo Committee for Ethical Aspects of Human Reproduction and Women's Health. Ethical issues in the management of severe congenital anomalies. Int J Obstet Gynecol 2013;120(3):307-308. DOI:10.1016/j.ijgo.2012.10.005

16. Hall DR, van Niekerk AA. Reconsidering counselling and consent. Dev World Bioeth 1 Dec 2015 (Epub ahead of print). DOI:10.1111/dewb.12100

17. Bennett R. When intuition is not enough. Why the principle of procreative beneficence must work much harder to justify its eugenic vision. Bioethics 2014;28(9):447-455. DOI:10.1111/bioe.12044

18. Soniewicka M. Failures of imagination: Disability and the ethics of selective reproduction. Bioethics 2015;29(8):557-563. DOI:10.1111/bioe.12153

19. Parfit D. Reasons and Persons. Oxford: Claredon Press, 1987:370.

20. Tong R. Genetic screening: Should parents seek to perfect their children genetically? In: Dickenson D, ed. Ethical Issues in Maternal-Fetal Medicine. Cambridge: Cambridge University Press, 2002:87-100.

21. Jacobs BM. Is there a moral obligation to select healthy children? J Med Ethics 2015;41(8):696-700. DOI:10.1136/medethics-2014-102400 